\title{
Will Decline in Foreign Trade Reshape Internal Economic Geography? Simulations in an Estimated Model of the Chinese Space-economy
}

\author{
Qiliang Mao ${ }^{1}$, Fei Wang ${ }^{2}$ \\ ${ }^{1}$ School of Urban Economics and Public Administration, Capital University of Economics and Business, Beijing, P. R. \\ China \\ ${ }^{2}$ School of Public Policy and Management, Tsinghua University, Beijing, P. R. China \\ Correspondence: Qiliang Mao, School of Urban Economics and Public Administration, Capital University of \\ Economics and Business, Beijing, P. R. China.
}

\author{
Received: November 7, 2016 Accepted: November 27, 2016 Online Published: November 27, 2016 \\ doi:10.11114/bms.v2i4.2018 URL: http://dx.doi.org/10.11114/bms.v2i4.2018
}

\begin{abstract}
This study evaluates the role of decline in foreign trade in shaping China's internal economic Geography. In a first step, we develop a multi-region multi-industry economic geography model under Cournot competition, of which we estimate the parameter values from real regional and industry data to obtain a predictable model. Next, we set some scenarios reflecting a decline in export to simulate the evolution of industrial spatial pattern. The simulations indicate the evident impact of decreasing export on the spatial distribution of industries; besides, the degree of influence varies across different industries. Moreover, the decline in export of one industry not only influences its own location, but also the location of the forward or backward-linked industries. However, the general spatial pattern, observed after policy reforms and trade liberalization, will not be reversed due to export recession in China.
\end{abstract}

Keywords: foreign trade, industry location, economic geography model, core-periphery

\section{Introduction}

Increasing globalization exerts a profound impact on the internal economic geography of a country. The "World Development Report 2009: Reshaping Economic Geography" pointed out that globalization may readjust the spatial pattern of production in a country, and China's current economic landscape is an expressive portrayal of this impact. In the era of planned economy, as China advocated the development of heavy industry in its inland, the majority of national investments flowed to the inland provinces, and a large number of industries moved from the coastal areas to inland provinces. However, after the policy reforms and trade liberalization, and China's integration into the world economy as the gateway to overseas markets, the coastal areas flourished again by virtue of unique geographical advantages and preferential policies, while the development of China's inland areas was subject to several policy barriers. The eastern coastal areas progressed faster than the inland areas in terms of industrialization, urbanization, and concentrated economic activities, becoming the "economic center" of China, while the inland areas became a "periphery" (Huang, 2011). However, due to the global financial crisis in recent years, the role of the international market in China's economic growth has weakened. The regions in the real economy that were the most affected by the financial crisis were the enterprises engaged in the export of labor-intensive products in the coastal areas of China (Cai et al., 2009). In addition, the present GDP) growth of the eastern coastal provinces, which were once flourishing in the export-oriented economy of China, is significantly lower than that of the central and western provinces. Globalization, once again, exerts an impact on the coastal-inland difference in China's economic geography. Changes in the international markets and fluctuations in foreign trade have become the focal points that affect the economic spatial pattern of China. Previous research on the changes in spatial distribution of domestic economic activities under the fluctuations of international trade environment would be useful analyses as well as important data in the study of the evolution mechanisms of economic geography.

Systematic study has been conducted in spatial economics on the influence of foreign trade on the internal economic geography of a country. When a country's economy is relatively closed, the domestic market potential becomes a primary decisive factor; however, once a country begins foreign trade operations, accessibility to the international market becomes remarkably important, and the border regions or coastal areas frequently benefit from their 
geographical location. Krugman and Livas (1996) pioneered the core-periphery model of two countries and three areas by adding foreign trade, and Alonso-Villar (1999), Plauzie (2001), and Crozet and Soubeyran (2004) developed theoretical models of foreign trade and economic geography on the basis of the core-periphery model. Theoretical research implies that international trade will promote changes in economic geography and drive economic activities to relocate to areas favoring international trade. Brülhart (2011) concluded that spatial characteristics of the relocation effect depend on the initial spatial distribution of economic activities of a country. If a country's economic center is consistent with areas that have geographical advantages in foreign trade, it will further strengthen the economic concentration; on the contrary, foreign trade will collapse the original concentration to promote the spread of economic activities to areas with geographical advantages. These theoretical predictions have been validated by objective facts, such as Krugman and Livas (1996) found that since the establishment of the North American Free Trade Agreement (NAFTA), economic geography of Mexico had undergone significant changes; that is, economic concentration declined in the traditional center, Mexico City; and instead, a new industrial belt arose in the US-Mexican border region. Hanson (1998) discovered similar results and he argued that, before trade liberalization, the distance from Mexico City was the primary factor in determining market potential, before the distance from the United States became equally important. Tomiura (2003) found that the historic exchange rate appreciation due to the "Plaza Accord" had significantly changed the geographic distribution of manufacturing; in addition, the research detected a significant decline in industrial concentrations that were previously established near output consumers, especially in high-growth industries with a significant market share.

The experience of Mexico and Japan could be helpful to China. After the policy reform and trade liberalization, and especially after joining the World Trade Organization, foreign trade increased rapidly and became one of the main driving forces of economic growth in China (Liu et al., 2010; Hu and Zhang, 2015). Similar to Mexico, economic activities gradually concentrated in areas with geographical advantages for foreign trade, and eastern coastal provinces became an agglomeration of industry and foreign direct investment (Fujita and Hu, 2001; Wen, 2004; Huang and Li, 2006; He and Xie, 2006; Liu et al., 2007). Similar to the situation in Japan after the "Plaza Accord," the recent global financial crisis lead to a significant decline in exports, and had a huge impact on the domestic industrial development in all regions in China. Liu et al. (2010) pointed out that the influence of the decline in export on economic growth of different provinces varied with their dependence on export. Yangtze River Delta and Pearl River Delta suffered the most, as the contribution rate of exports to regional GDP growth in these regions was significantly higher than the other coastal areas and inland provinces. In addition, many scholars have focused on the influence of changes in international trade environment on the internal economic geography of China. Zuo and Paget (2015) argued that changes in foreign trade had contributed to the regional convergence in China. On the one hand, global financial crisis has negatively affected the development of the regional economy, especially eastern coastal areas, and on the other hand, some industries, especially traditional labor-intensive industries, are losing their low labor cost advantage-exports of which will gradually decrease predictably. Decreasing share in the international market will weaken the geographical advantages of eastern coastal areas, which may help to promote the spread of industries to other lagging regions. Xu and Liang (2012), from a study based on the new economic geography model, discovered that deterioration of external economic demand would promote the tendency of industries to transfer from the coastal areas to the inlands. Therefore, a study that aims to examine the influence of the international trade environment on internal economic geography is of huge importance.

However, studies usually tend to focus on the impact of international trade liberalization on the domestic economic geography rather than the impact of the decreasing foreign trade on industrial location changes. The difference between both the concepts has been explained by Brülhart et al. (2004), who argued that trade liberalization was indeed conducive for non-dependent industries to locate to border areas; however, this could change in certain situations. When the impact of the changing external market on industrial location is not large enough to offset the dependence and positive externalities of the existing industrial concentration, the location change will become unpredictable. China has formed a spatial pattern with economic activities concentrated in eastern coastal regions; and agglomeration economies, market access, path dependence and other similar factors are strong centripetal forces attracting industries to those areas. It is of urgent need to make in-depth and cautious analyses on the manner and extent of change to the external market in transforming the established pattern. Liu et al. (2009) stated that the global financial crisis has led to a significant decline in exports and has had an extremely uneven impact on the regional economic development in China. Although there was a consensus among the study group that coastal areas were the worst affected, quantitative analyses on the concrete impact would be carried out further. Since the global financial crisis occurred in the past few years, very little data was available for in-depth analyses. In addition, industrial location will be influenced by changes in the trade environment; however, economic spatial pattern may not be immediately affected by a short-term crash. Therefore, it is feasible to carry out scenario simulation and prediction by using certain approaches. 
Proper scenario simulation and prediction on the changes in industrial location should be conducted based on an equilibrium framework, and effectively analyze the interdependence among different spatial economic sectors to comprehensively measure the implications of certain changes. Currently, the core-periphery model of spatial economics is deemed as a mature research framework. Spatial economics applies the general equilibrium theory to industrial location studies, which has become a major framework for research; however, the stable equilibrium of the model is denoted by a set of nonlinear equations, which cannot be completely solved analytically. This makes it necessary to resort to simulations and, thus, to assign values. Whereas, as Combes et al. (2008) argued, the interest of such exercises is questionable, and setting these values is often an arbitrary process as there is not a lot of value-add in extending models to more regions or sectors when the parameter values have to be arbitrarily assigned. In contrast, simulations are much more useful when one has access to parameter values that have been estimated from real data. Guided by this idea, scholars began to apply real data to spatial equilibrium calculations. For example, Smith and Venables (1988) and Haaland and Norman (1992) conducted inspirational studies, and Combes and Lafourcade (2001) proposed a more mature approach in the form of a tractable economic geography model. They established models based on spatial economic theories in the framework of increasing returns and imperfect competition; added intermediate products to models through input-output matrix; estimated parameter values from real data of mass regions and sectors, and further used these estimated values for simulation. In this case, when a large-scale model has not been rejected in the first phase of econometric estimation, it is admissible and potentially illuminating to simulate it (Combes et al., 2008). Utilizing the "Theory with Numbers" (Combes et al., 2008), we can accurately explain how spatial equilibrium is realized in the real world in terms of an economic geography model, which aims to apply theoretical models to the real world with real data and to move away from the $2 \times 2 \times 2$ framework. Teixeira (2006) stated that the other important advantage of the model was the ability to verify the prediction of the new economic geography model on industry location.

The study aims to predict the impact of foreign trade decline on the future spatial pattern of manufacturing industries in China by adopting the tractable economic geography model proposed by Combes and Lafourcade (2001), to provide a unique perspective of spatial analysis on the development trends of the regional economy in China. Spatial linkage is regarded as the basis of the location of economic activities and regional development (Isard, 1956), and is particularly deemed as the medium of external trade environment affecting domestic spatial pattern of industry, in our study. Therefore, the key objective of the study or the premise of prediction is to estimate the spatial linkage across domestic industrial activities by using a multi-region multi-industry economic geography model. In a first step, we incorporate foreign trade into the existing model to improve the endogenous mechanism of industrial location in China. We then turn to estimate the model's key parameters from the regional and industrial data to acquire a predictive model. Third, scenario simulations implement to see the impact of changes in foreign trade on China's internal economic geography. Moreover, we show details on the changes and distinctions of heterogeneous industrial distribution across regions.

The remainder of the study proceeds as follows. Chapter 2 establishes the multi-region multi-industry economic geography model and the derivation of a structurally estimable specification. Chapter 3 presents the French data we use and the estimation results. Chapter 4 applies scenario analysis for the simulation and prediction of the evolution of future spatial pattern of industry under different foreign trade situations. Chapter 5 concludes.

\section{The Economic Geography Model}

To assess the empirical spatial relation industries, we first have to extend the standard 2-region/2-industry framework of new economic geography. We then derive a linear specification from new multi-region/multi industry model that we estimate using Chinese regional data.

\subsection{Theoretical Model}

\subsubsection{Production Function}

Consider an economy composed of $J$ regions, $j=1, \ldots, J$, and $S$ industries, $s=1, \ldots, S$. Within industry s, every single-plant firms operate in region $j$ where they produce the same homogenous good. We assume that technology differs across industries but not across regions. The Cobb-Douglas production function of a representative firm operating in industry $\mathrm{s}$ and region $\mathrm{j}$ is

$$
\begin{gathered}
y_{j}^{S}=\left(l_{j}^{S}\right)^{\alpha^{S}} \prod_{z}\left(K_{j}^{z}\right)^{\beta^{z}}, \alpha^{S}+\sum_{z} \beta^{z}=1 \\
C_{j}^{S}=l_{j}^{S} w^{S}+\sum_{z} K_{j}^{z} p_{j}^{z}+f_{j}^{S}
\end{gathered}
$$

Where $y_{j}^{s}$ represents the total output, $l j \mathrm{~s}$ is the number of employees and $K_{j}^{z}$ is the quantity of good $z$ used as intermediate input. $\alpha^{s}$ and $\beta^{z}$ are constant parameters. Moreover, we assume that firms incur fixed production costs, $f_{j}^{s}$, which differs both across industries and regions. 
Let $c_{j}^{s}$ denote the marginal cost of production in industry $\mathrm{s}$ and region $\mathrm{j}$ and $p_{j}^{z}$ is price. Under technology (1), marginal cost is given by

$$
c_{j}^{S}=\frac{\left(w^{S}\right)^{\alpha^{S}} \Pi_{z}\left(p_{j}^{z}\right)^{\beta^{Z}}}{\left(\alpha^{S}\right)^{\alpha^{S}} \prod_{z}\left(\beta^{z}\right)^{\beta^{z}}}
$$

where $w^{s}$ is the wage in industry s, which doesn't vary across regions. For the representative firm operating in industry $\mathrm{s}$ and region $\mathrm{j}$, labor and intermediate demands are therefore:

$$
l_{j}^{s}=\alpha^{s} \frac{c_{j}^{s} y_{j}^{s}}{w^{s}}, \quad K_{j}^{z}=\beta^{z} \frac{c_{j}^{s} y_{j}^{s}}{p_{j}^{z}}, \forall \mathrm{z}
$$

\subsubsection{Consumer Demand and Good-market Equilibrium}

Let $Q_{j}$ s denote the final consumption of good $\mathrm{s}$ in region $\mathrm{j}$, and $\gamma_{\mathrm{s}}$ the share of good $\mathrm{s}$ in consumers' expenditure. $R_{j}$ is the consumer income in region $\mathrm{j}$ which is sum of the local (endogenous) wage bill.

$$
R_{j}=\sum_{z} w^{z} n_{j}^{z} l_{j}^{z}
$$

Globalization has made foreign trade an important factor affects regional production. The total demand for good $\mathrm{s}$ in region $\mathrm{j}, D_{j}^{S}$ is the sum of final consumption, $Q_{j}^{S}$, intermediate inputs, $I_{j}^{S}$ and foreign demand, $E_{j}^{S}$, which export of good $\mathrm{s}$ for region $\mathrm{j}$. Let $\mathrm{p}_{\mathrm{j}}^{\mathrm{s}}$ denote the sale price in region $\mathrm{j}$ and FOB price. $d_{j p}$ is additive trade cost of delivering one unit of good $s$ from region $\mathrm{j}$ to a nearest port, $d_{j p} \geq 1$. If region $\mathrm{j}$ has a port, FOB price is the same with local price. But if region $\mathrm{j}$ is not in coastal area, transport cost should be added to be FOB price. $\mathrm{R}_{\mathrm{j}}^{\mathrm{s}}$ denotes the domestic consumption and $\mathrm{FD}_{\mathrm{j}}^{\mathrm{S}}$ is the foreign demand for good $\mathrm{s}$ in region $\mathrm{j}$.

$$
\begin{gathered}
D_{j}^{S}=Q_{j}^{S}+I_{j}^{S}+E_{j}^{S} \\
\left\{\begin{array}{l}
Q_{j}^{S}=\frac{\gamma^{s} R_{j}}{p_{j}^{S}} \\
I_{j}^{S}=\sum_{z} n_{j}^{Z} k_{j}^{z S} \\
E_{j}^{S}=\frac{E^{s}}{d_{j p} p_{j}^{s}}
\end{array}\right. \\
\left\{\begin{array}{l}
R_{j}^{S}=\gamma^{s} R_{j}+\sum_{z} \beta^{s z} c_{j}^{S Z} n_{j}^{z} y_{j}^{S Z} \\
F D_{j}^{S}=\frac{E^{s}}{d_{j p}}
\end{array}\right.
\end{gathered}
$$

Then we consider the whole country in the framework of demand and production. Let $y_{i j}^{s}$ denote consumption of good $\mathrm{s}$ in region $\mathrm{j}$ from region $\mathrm{i}$ (including region $\mathrm{j}$ ). Total demand of goods in region $\mathrm{j}$ equals sums of the supply from each domestic region and oversee exports.

$$
\sum_{i} n_{i}^{S} y_{i j}^{S}=\frac{R_{j}^{S}}{p_{j}^{S}}+\frac{E^{S}}{d_{j p} p_{j}^{S}}
$$

\subsubsection{Firms' Strategies under Cournot Competition}

Due to trade cost, domestic markets are segmented. Let $t_{j i}^{S}$ denote the additive trade cost of delivering one unit of good $\mathrm{s}$ from region $\mathrm{j}$ to region $\mathrm{i}$. The profits of a representative firm of industry s located in region $\mathrm{j}$ can be written as

$$
\pi_{j}^{S}=\sum_{i}\left(p_{i}^{S}-c_{j}^{S}-t_{j i}^{S}\right) y_{j i}^{S}-f_{j}^{S}
$$

We assume that firms behave as Cournot-Nash oligopolists. Each firm chooses non-cooperatively and strategically the quantity it produces for each market. It maximizes its profit with respect to $y_{j i}^{S}$, taking into account its impact on prices and taking the quantities produced by all other firms as given. The first order conditions are given by

$$
\frac{\partial \pi_{j}^{s}}{\partial y_{j i}^{S}}=p_{i}^{S}-c_{j}^{S}-t_{j i}^{S}-\frac{p_{i}^{S} y_{j i}^{S}}{D_{i}^{S}}=0, \forall i
$$

Firms in region $j$ produce for market $i$ unless the marginal profit in this market is negative $\left(p_{i}^{s}-c_{j}^{S}-t_{j i}^{S}<0\right)$. If this latter does not hold, the corner solution is given by $y_{j i}^{S}=0$. Numbers of firms, price and quantities is as follows.

$$
N^{s}=\sum_{j} n_{j}^{s}
$$




$$
\begin{gathered}
p_{j}^{S}=\frac{\sum_{i} n_{i}^{S} t_{j i}^{S}+\sum_{i} n_{i}^{S} c_{i}^{S}}{N^{S}-1} \\
y_{j i}^{S}=\frac{p_{i}^{S}-c_{j}^{S}-t_{j i}^{S}}{\left(p_{i}^{S}\right)^{2}}\left(R_{i}^{S}+\frac{E^{S}}{d_{j p}}\right), \forall i
\end{gathered}
$$

\subsubsection{Spatial Equilibrium}

In the short-run equilibrium, the number of firms is exogenous. The short-run equilibrium is thus given by Eqs. (3), (5), (7), (12), and (13), unless the marginal profit is negative, in which case $y_{j i}^{S}=0$. The area-industry price comes from Eqs. (3) and (12). Eqs. (5), (8) and (13) lead to the expression of quantities as a function of exogenous $n_{j}^{s}$. In the long-run equilibrium, the number of firms in each industry and region adjusts such that $\pi_{j}^{S}=0$, which endogenizes $n_{j}^{S}$.

\subsection{Estimable Specification}

So far, we build up a theoretical general spatial equilibrium model involved multi regions and multi industries. In order to estimation key parameters by applying Chinese regional data, we need to transform the theoretical model into linear regression model in next step. Data on value-added, capital, price, or intermediate input costs do not exist in China at the disaggregated spatial scale. However, data on employment and number of firms are available. Our baseline estimation therefore builds on firm labor demand. We derive a specification of area-industry employment per firm $l_{j}^{S}$ from the equilibrium conditions, which allows us to estimate the model parameters that are missing in Chinses data. Eqs. (3) and (4) and $y_{j}^{S}=\sum_{i} y_{j i}^{S}$, yield

$$
l_{j}^{S}=\frac{\left(\alpha^{S}\right)^{1-\alpha^{S}} \prod_{z}\left(p_{j}^{z}\right)^{\beta^{Z}}}{\left(w^{S}\right)^{1-\alpha^{S}} \prod_{z}\left(\beta^{z}\right)^{\beta^{z}}} \sum_{i} y_{j i}^{S}
$$

Next, we plug Eqs. (3), (8), (12), and (13) back into Eq. (14) gives $l_{j}^{s}$ as a function of the number of firms, employment and trade costs from all area and industry sources, in addition to local wages, technology and budget coefficients. We have Chinese data on all of these, except for trade costs. However, detailed data on mileage, $t_{i j}$, are available for any pair of regions $i$ and $j$. We assume that trade costs per unit exported, $t_{i j}^{s}$, are proportional to these mileage. Denoting by $\tau^{s}$ the coefficient of proportionality for industry s, we assume that:

$$
t_{i j}^{s}=\tau^{s} t_{i j}
$$

As $\tau^{S}$ are the only model parameters not available in real Chinese data, we need to estimate them. Note that, to be theory-consistent, the estimated $\tau^{s}$ should be positive. Significantly negative estimates mean that either our transport-mileage data do not reflect real trade costs, or that our Cournot competition economic geography model is incorrect.

Unfortunately, after plugging equilibrium prices and exports back into the labor specification (14), the expression for $l_{j}^{s}$ is not $\tau^{s}$-linear. To make the econometrics simple, we linearize expression (14) with respect to $\tau^{s}$ by using a first-order Taylor expansion.

First, let $p^{s}$ denote the price of intermediates when manufactured goods were to be traded at zero cost across regions. From Eqs. (3) and (12), we have:

$$
p^{S}=\frac{N^{s}\left(w^{s}\right)^{\alpha^{s}}}{\left(N^{s}-1\right) B^{s}} P^{s}
$$

with $B^{s}=\left(\alpha^{s}\right)^{\alpha^{s}} \prod_{z}\left(\beta^{z}\right)^{\beta^{z}}$, and where $P^{s}=\prod_{z}\left(p_{j}^{z}\right)^{\beta^{z}}$ is the price index for intermediate inputs that would prevail if markets were to be perfectly integrated.

From Eq. (16), the explicit expressions for $p^{s}$ are derived by solving the system:

$$
\left(\begin{array}{c}
\log \left(p^{1}\right) \\
\vdots \\
\log \left(p^{S}\right) \\
\vdots \\
\log \left(p^{S}\right)
\end{array}\right)=\left(\begin{array}{ccccc}
\beta^{11} & \cdots & \beta^{S 1} & \cdots & \beta^{S 1} \\
\vdots & \vdots & \vdots & \vdots & \vdots \\
\beta^{1 S} & \cdots & \beta^{S S} & \cdots & \beta^{S S} \\
\vdots & \vdots & \vdots & \vdots & \vdots \\
\beta^{1 S} & \cdots & \beta^{S S} & \cdots & \beta^{S S}
\end{array}\right) \times\left(\begin{array}{c}
\log \left(p^{1}\right) \\
\vdots \\
\log \left(p^{S}\right) \\
\vdots \\
\log \left(p^{S}\right)
\end{array}\right)+\left(\begin{array}{c}
\log \left(\frac{N^{1}\left(w^{1}\right)^{\alpha^{1}}}{\left(N^{1}-1\right) B^{1}}\right) \\
\vdots \\
\log \left(\frac{N^{S}\left(w^{S}\right)^{\alpha^{S}}}{\left(N^{S}-1\right) B^{S}}\right) \\
\vdots \\
\log \left(\frac{N^{S}\left(w^{S}\right)^{\alpha^{S}}}{\left(N^{S}-1\right) B^{S}}\right)
\end{array}\right)
$$

However, markets are not perfectly integrated. Let $\delta_{j}^{S}$ represents the relative gap between the price that would prevail 
were markets to be perfectly integrated and the area-specific price related to the segmented case. We assume that $\delta_{j}^{s} \mathrm{~s}$ is small enough (compared to 1) to let us consider the first-order terms of the Taylor expansion only. The equilibrium area-industry price is:

$$
p_{j}^{S}=p^{s}\left(1+\delta_{j}^{S}\right)
$$

From Eqs. (3), (8) and (18), we can derive the following $\mathrm{J} \times \mathrm{S}$ system for $\delta_{j}^{s}$ terms:

$$
\delta_{j}^{S}=\frac{1}{N} \sum_{i} n_{i}^{S} \sum_{z} \beta^{z s} \delta_{j}^{z}+\frac{\tau^{s}}{p^{s}\left(N^{s}-1\right)} \sum_{i} n_{i}^{S} t_{i j}
$$

These expressions can be written in the following matrix form:

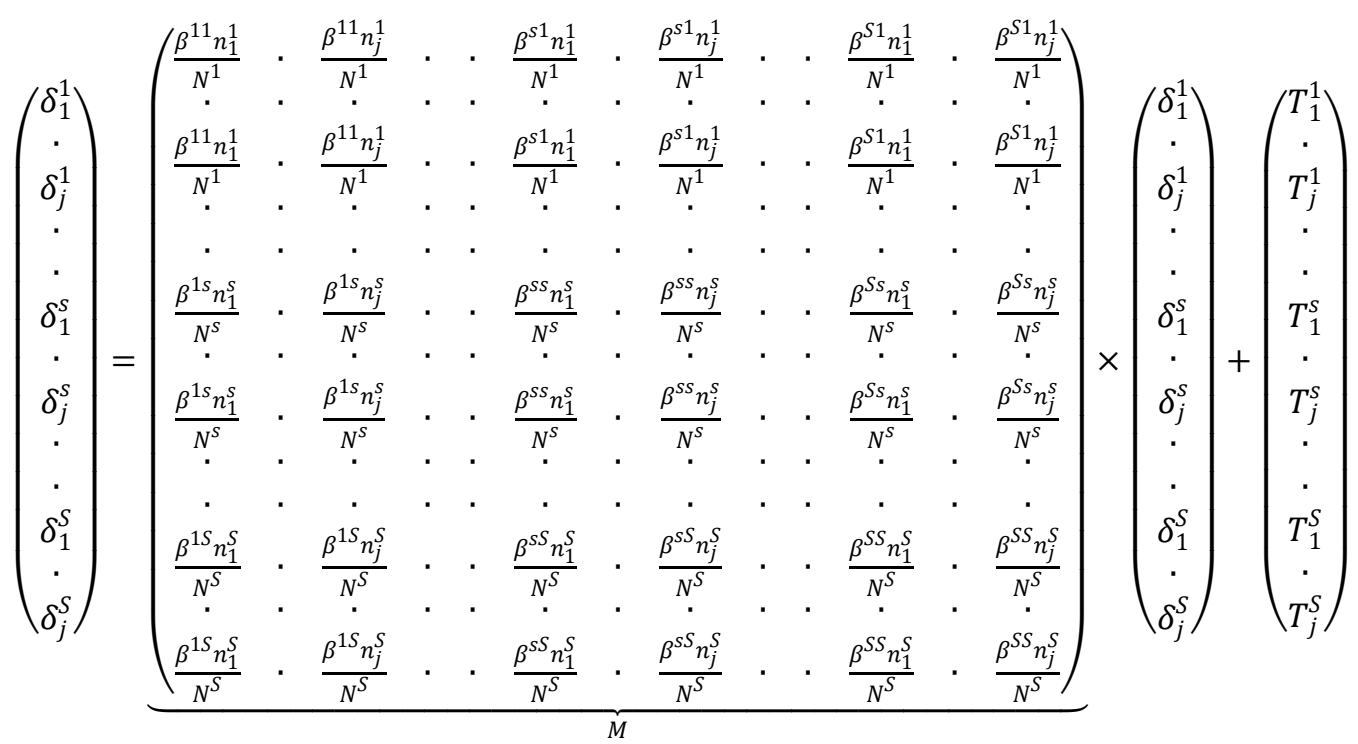

Where $T_{j}^{S}=\frac{\tau^{s}}{p^{s}\left(N^{S}-1\right)} \sum_{i} n_{i}^{S} t_{i j}$

Thus, the solution of this linear system can be written as:

$$
\begin{gathered}
\delta_{j}^{s}=\sum_{z} \tau^{z} X_{j}^{Z s} \\
X_{j}^{Z s}=\frac{1}{p^{z}\left(N^{z}-1\right)} \sum_{i} b_{i j}^{Z s} \sum_{k} n_{k}^{z} t_{i k},
\end{gathered}
$$

with $b_{i j}^{z S}$ being the generic term for the inverse of the $\left(I_{J \times S}-M\right)$ matrix, and $I_{J \times S}$ the identity matrix of size $\mathrm{J} \times \mathrm{S}$. Hence, the computation of the $b_{i j}^{z S}$ parameters requires the inversion of a matrix whose size is the number of industries times the number of areas, that is $9099 \times 9099$ at most for the industrial and geographical levels we choose for our baseline estimation.

We can now write $\tau^{s}$-linear expressions for the area-industry marginal cost of production and price, given by:

$$
\left\{\begin{array}{l}
p_{j}^{s}=p^{s}\left(1+\sum_{z} \tau^{z} X_{j}^{z s}\right) \\
c_{j}^{s}=\frac{\left(w^{s}\right)^{\alpha^{s}} P^{s}}{B^{s}}\left(1+\sum_{z^{\prime}} \tau^{z^{\prime}} \sum_{z} \beta^{z s} X_{j}^{z z^{\prime}}\right)
\end{array}\right.
$$

Finally, Eqs. (12) and (24) allow us to compute $\tau^{s}$-linear expressions for the quantities sold in each region, then we deduce the total production of a representative firm in each region and industry:

$$
\begin{aligned}
& y_{j}^{S}=\frac{\left(p^{S} B^{S}-p^{S}\left(w^{S}\right)^{\alpha^{S}}\right)}{\left(p^{S}\right)^{2} B^{S}} \sum_{i}\left(R_{i}^{S}+\frac{E^{S}}{d_{j p}}\right)\left[1+\tau^{S}\left(w_{i j}^{S S}-2 X_{i}^{S S}\right)+\sum_{z \neq s} \tau^{Z}\left(w_{i j}^{Z S}-2 X_{i}^{z S}\right)\right]
\end{aligned}
$$

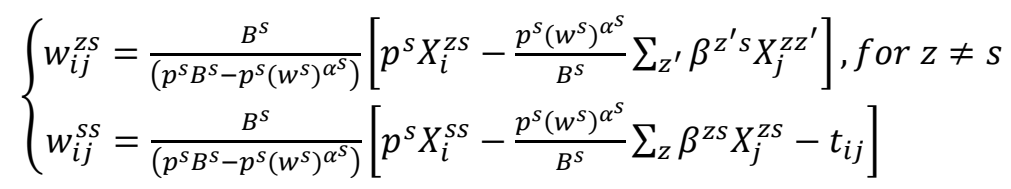

From Eq. (25) and the linearization of Eq. (3), the final $\tau^{s}$-linear expression for employment per firm is given by Eq. 
(27), which is also the estimable linear labor demand specification.

where

$$
l_{j}^{s}=\theta^{s}+\tau^{s} Z_{j}^{s}+\sum_{z \neq s} \tau^{z} Z_{j}^{z s}+\varepsilon_{j}^{s}
$$

$$
\begin{aligned}
& \left\{\begin{array}{l}
Z_{j}^{s}=H^{s} \sum_{i}\left(R_{i}^{s}+\frac{E^{s}}{d_{j p}}\right)\left[F^{s}\left(X_{i}^{s s}-\sum_{z^{\prime}} \beta^{z^{\prime} s} X_{j}^{s Z^{\prime}}\right)-t_{i j}\right] \\
Z_{j}^{z s}=F^{s} \sum_{i}\left(R_{i}^{S}+\frac{E^{s}}{d_{j p}}\right)\left(X_{i}^{z s}-\sum_{z^{\prime}} \beta^{z^{\prime} s} X_{j}^{z Z^{\prime}}\right) \\
\theta^{s}=G^{s} \sum_{i}\left(R_{i}^{S}+\frac{E^{s}}{d_{j p}}\right)
\end{array}\right. \\
& \left\{\begin{array}{l}
H^{s}=\frac{\alpha^{s} p^{s}}{\left(p^{s}\right)^{2} B^{s}\left(w^{s}\right)^{1-\alpha^{s}}} \\
F^{s}=\frac{2 p^{s}\left(w^{s}\right)^{\alpha^{s}}-p^{s} B^{s}}{B^{s}} \\
G^{s}=\frac{\left(p^{s} B^{s}-p^{s}\left(w^{s}\right)^{\alpha^{s}}\right) \alpha^{s} p^{s}}{\left(p^{s} B^{s}\right)^{2}\left(w^{s}\right)^{1-\alpha^{s}}}
\end{array}\right.
\end{aligned}
$$

\section{Data and Estimations}

\subsection{Data}

The geographical unit of analysis is the prefecture-level-and-above area. This study only examines the situation of mainland China, while Hong Kong, Macau, and Taiwan are not included. Beijing, Tianjin, and Shanghai are taken as the prefectural level area for similar sized areas. In total, the data is from 337 prefectural level units. This study only discuss the segmented industry of manufacturing, and excludes mining and public utilities industries like logging, power, and gas, as these industries highly rely on local natural resources or local demand. The study includes 27 sub-industries of manufacturing, according to industry classification of industrial census and economic census, using 2-digit industries. Specific-area industry data is collected from the Annual Survey of Industrial Firms dataset, which is conducted by the National Bureau of Statistics in China. This dataset contains all state-owned enterprises and non-state-owned enterprises with annual sales of more than 500 million Yuan. The dataset provides detailed information on the firms' identification, operations and performance, including location, industry code, and employment. We derive the technology and preference parameters, $\alpha^{S}$ and $\beta^{z}$, by combining the national input-output matrices of China in 2007. The same source is used for nominal wages by industry, $w^{\text {s }}$. Regional GDP, population, and areas are from China Statistical Yearbook for the regional economy for corresponding years. Highway mileage among regions is from the electronic edition of China Traffic Map.

\subsection{Baseline Estimation}

Our first panel includes 337 prefectures and 27 industries, so Eq. (27) involves 28 different variables: $Z_{j}^{s}, Z_{j}^{z s}(z \neq s)$ and $\theta^{s}$. We render the specification slightly more general by introducing industry fixed effects rather than the real $\theta^{s}$. We also include prefecture fixed-effects to capture any unobservable time-invariant location characteristics. Even if geography is partly reflected in segmented markets, other exogenous geographic features, such as climate, public and private capital endowments and local amenities, should be controlled for. We hence estimate the following:

$$
l_{j}^{S}=\tau^{s} Z_{j}^{S}+\sum_{z \neq s} \tau^{z} Z_{j}^{z s}+\mu_{j}+\mu^{s}+\varepsilon_{j}^{s}
$$

where $\mu_{j}$ and $\mu^{s}$ are the EA and Industry fixed effects, respectively. Table 1 reports the Ordinary least squares estimation results of Eq. (29).

To be consistent with the prediction of the theoretical model, estimated $\tau$ of all industries are positive, which logically validates the framework. Estimated $\tau$ is significantly positive in $1 \%$ confidence level for most industries; significantly positive in $1 \%$ confidence level for stationery, educational and sports goods manufacturing as well as electronic and telecommunications, while not as significantly positive for special equipment manufacturing. This estimation results show that the model is reliable to simulate the evolution of industrial spatial pattern in China.

In order to make further analysis on the reliability of estimated value, we introduce estimated value and other variables with real data into the model (29) to simulate employment of each industry for every region. Then we apply the Pearson correlation analysis between the simulated value and the real region-specific employment for each industry. The higher the correlation, the better the simulation will be. The results show (in Table 2) that simulated region-specific employment of all industries has a significant positive correlation with the real region-specific employment. Pearson 
Correlation in most industries is more than 0.8 , while the correlation in some industries is up to 0.9 , and only a few industries have a correlation between 0.6-0.7. In order to show such a correlation visually, we symbolized the real spatial distribution of the industry as well as the simulated one. Due to space constraints, we only chose two typical industries for display. From Figure 1, we recognize that the basic pattern of real spatial distribution is well revealed by the simulated results. For garments \& other fiber products, simulated distribution detects the actual general gradient from the east to the west, and from the coast to the inland. Hence, our analysis reinforces that the model is reliable for the simulation of industrial spatial distribution in China, which also means that the model with estimated $\tau$ can be used to predict the impact of foreign trade changes on industrial spatial pattern.

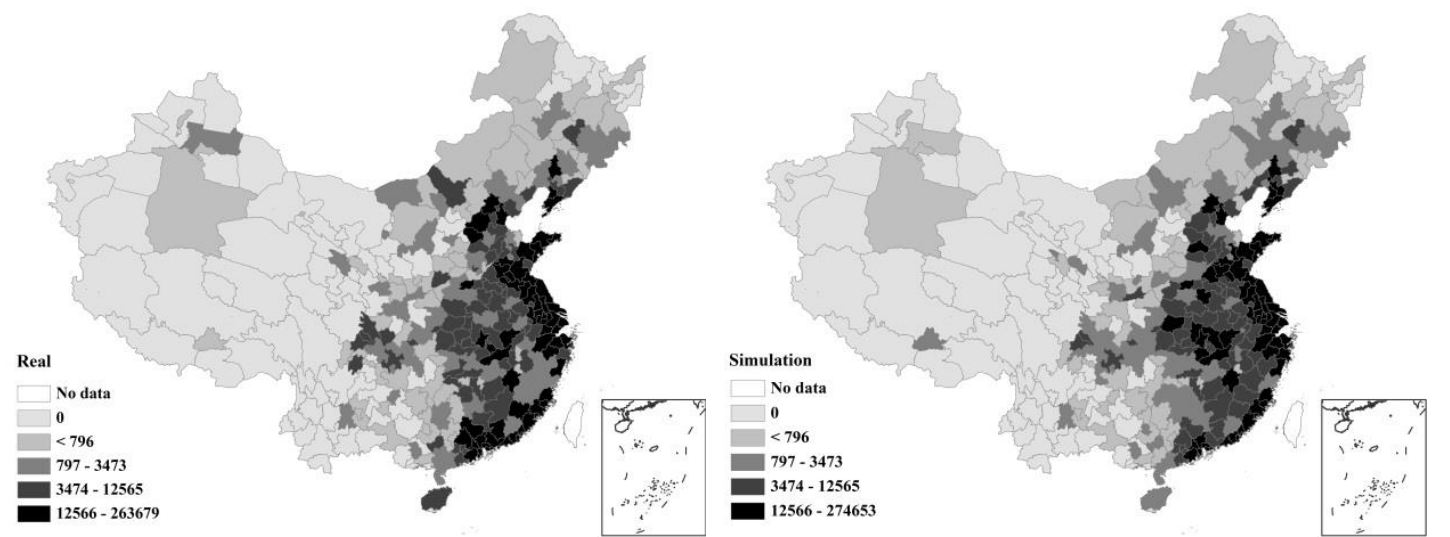

Figure1. Total employment across regions in China for garments \& other fiber products industry: real (left) and simulated (right)

Table 2. Pearson correlation between simulated value and real employment for region-specific industry

\begin{tabular}{cccccc}
\hline industry & Correlation & industry & Correlation & industry & Correlation \\
\hline 1 & $0.8651 * * *$ & 10 & $0.8272 * * *$ & 19 & $0.6480^{* * *}$ \\
2 & $0.8377 * * *$ & 11 & $0.6864 * * *$ & 20 & $0.6825^{* * *}$ \\
3 & $0.6485^{* * *}$ & 12 & $0.6034 * * *$ & 21 & $0.9308^{* * * *}$ \\
4 & $0.9452^{* * *}$ & 13 & $0.9101 * * *$ & 22 & $0.9364 * * *$ \\
5 & $0.9042 * * *$ & 14 & $0.7879 * * *$ & 23 & $0.8849 * * *$ \\
6 & $0.8628 * * *$ & 15 & $0.7661 * * *$ & 24 & $0.8843 * * *$ \\
7 & $0.8864 * * *$ & 16 & $0.8385 * * *$ & 25 & $0.8528 * * *$ \\
8 & $0.8101 * * *$ & 17 & $0.7651 * * *$ & 26 & $0.9057 * * *$ \\
9 & $0.8553 * * *$ & 18 & $0.8838^{* * *}$ & 27 & $0.7668 * * *$ \\
\hline
\end{tabular}

Note: $*$ significant at $10 \%$ level; $* *=$ significant at $5 \% ; * * *=$ significant at $1 \%$.

\section{Simulations in the Chinese Space-economy}

Foreign trade contributed to the industrial development in China. However, the ratio of exports in China's GDP started decreasing from 2006 (in Table 3), particularly, after the international financial crisis. As recession in foreign trade is not easy to understand, we have chosen to ignore the concept arguing in our study. To focus on the evolvement of economic geography, we introduce a decline in export ratio in GDP to measure recession of foreign trade.

Table 3. Industry-specific ratio of export in output value

\begin{tabular}{cccccc}
\hline Industry & Export $(\%)$ & Industry & Export $(\%)$ & Industry & Export $(\%)$ \\
\hline 1 & 5.1 & 10 & 5.4 & 19 & 9.1 \\
2 & 5.3 & 11 & 60.3 & 20 & 7.2 \\
3 & 4.1 & 12 & 3.6 & 21 & 20.1 \\
4 & 32.6 & 13 & 10.3 & 22 & 13.2 \\
5 & 34.4 & 14 & 9.5 & 23 & 17.1 \\
6 & 26.8 & 15 & 5.9 & 25 & 10.0 \\
7 & 12.2 & 16 & 31.4 & 26 & 25.1 \\
8 & 36.4 & 17 & 11.6 & 27 & 51.9 \\
9 & 3.8 & 18 & 6.5 & 66.3 \\
\hline
\end{tabular}

Note: ratio of export in output value is calculated by data of China's input-output table in 2007.

\subsection{Decline in Export and Change of Spatial Concentration}

It is not necessary to analyze every industry; therefore, only the industries with a large ratio of export value in the total value of output, i.e., export ratio, are valid. We apply the locational Gini index (see appendix 1) to measure the spatial pattern in terms of spatial concentration. Table 4 lists the variation in spatial concentration caused by the decline in 
export ratio for representative manufacturing industries. The results indicate that there are evident differences across industries. In most industries, such as textile, garments \& other fiber products, rubber products, electric equipment and machinery, electronic and telecommunications, instruments, meters, cultural and official machinery, the locational Gini index shows an initial trend of reduction, which progresses to a trend of expansion. In other words, some coastal areas experience industry recession with the decline in export ratio, while some inland areas attract more industries to locate, which leads to a spatial dispersion. With further decrease in the export ratio and other such reasons, industries gradually reorganize their location and certain areas obtain lasting advantages, therefore new industry clusters are formed, and a reformed pattern of spatial concentration appears. Contrary to the above-mentioned industries, the locational Gini index of furniture manufacturing, stationery, educational and sports goods, metal manufacturing, etc., becomes bigger with the decreasing export ratio. This may seem odd, however, a possible explanation is that the decline in international market leads to an erosion of locational advantages of some coastal areas as compared to the central domestic market. However, the centers of coastal regions, such as Yangtze Delta, Pearl River Delta, etc. attract industries due to the centripetal forces of a large market potential and an industrial forward-backward linkage, which may lead industries to be concentrated in fewer regions. Other than the above-mentioned industries, changes in the textile industry are much more complicated, as its locational Gini index decreases initially and then increases along with a decrease in the export ratio. However, with a further decline in the export ratio, the locational Gini index of textile industries decreases again. A gradual decline in the export ratio indicates a weakening of the international market and a relative strengthening impact on the domestic market in industrial spatial distribution. The peculiar changes of the textile industry indicate the uncertainties of decreasing export on spatial distribution due to the complicated determinants of industrial location. From the above analysis, the changes in export have a certain influence on the spatial pattern of all industries; however, the degree and impact of the influence varies across industries. For spatial organization of economic activities, no matter how much the decline in the export ratio is, agglomeration is always one of the characteristics of spatial pattern. Although, in the short run, the industrial spatial pattern will be driven to a dispersion, the endogenous forces of spatial organization will always promote newly formed agglomerations.

Table 4. Decline of export ratio and variation of locational Gini index

\begin{tabular}{llllll}
\hline Industry & Current & $-20 \%$ & $-50 \%$ & $-80 \%$ & $-100 \%$ \\
\hline Textile Industry & 0.7874 & 0.7781 & 0.7816 & 0.7793 & 0.7792 \\
Garments \& Other Fiber Products & 0.8061 & 0.7993 & 0.7970 & 0.7975 & 0.8015 \\
Leather, Furs, Down \& Related Products & 0.8498 & 0.8295 & 0.8401 & 0.8526 & 0.8589 \\
Furniture Manufacturing & 0.7797 & 0.7963 & 0.8171 & 0.8480 & 0.8845 \\
Stationery, Educational \& Sports Goods & 0.8391 & 0.8393 & 0.8420 & 0.8493 & 0.8639 \\
Rubber Products & 0.7641 & 0.7576 & 0.7567 & 0.7617 & 0.7764 \\
Metal Products & 0.6324 & 0.6379 & 0.6555 & 0.6842 & 0.7178 \\
Electric Equipment \& Machinery & 0.7614 & 0.7534 & 0.7540 & 0.7603 & 0.7668 \\
Electronic \& Telecommunications & 0.8295 & 0.8088 & 0.8189 & 0.8301 & 0.8542 \\
Instruments, Meters, Cultural \& Official & & 0.7852 & 0.8281 & 0.8597 & 0.8834 \\
Machinery & 0.8088 & & & & \\
\hline
\end{tabular}

\subsection{Simulation for Spatial Evolution of Representative Industries}

In this section, we analyze the influence of decreasing export on the general spatial pattern of industry in terms of concentration and dispersion. Specific geographical features will be examined in the next section. It may not be necessary to analyze all the industries involved in this article, so we select a few industries with a large export ratio. To correspond to the theoretical model, we chose industries in terms of input-output properties (final consumption goods and intermediate goods), and the upstream and downstream industries respectively related to the selected sectors. According to China's input-output table in 2007, we selected garments and other fiber products as the final consumption goods industry, and the textile industry as its upstream industry. In addition, the electric equipment and machinery is selected as the intermediate goods industry, and electronic and telecommunications as its downstream industry.

\subsubsection{Simulation for Spatial Evolution of Final Consumption Goods and Its Upstream Industry}

Figure 2 describes the ratio changes of each region in the entire country in terms of employment under continuous decline in export of the garments industry in China. The result shows that under the current export condition, east coast and south coast are the main concentration regions that account for about $70 \%$ of the entire country's employment, and the rest are located in the north coast and central China. Very few garments industries are located in the northeast, while the west region only accounts for less than 5\% employment of the entire country. However, with the reduction in export ratio, the northeast is likely to remain the main growth region where the ratio of industry employment is increasing remarkably, while the other regions are experiencing recession on a different level. Until the industrial export amount settles at zero, the northeast will remain the main industry concentrated region, outranked only by the east coast and south coast. We further investigate the spatial pattern of industrial growth across regions by calculating Getis-Ord $\mathrm{Gi}^{*}$ 
(see appendix 2) statistics in terms of employment in the context of current exports to zero exports. As shown in Figure 3, most areas of Liaoning and Jilin in the northeast are the main hotspots of growth, while the coastal regions like Yangtze River Delta, coast of Fujian and Shandong Peninsula are the main recession regions. By comparing the spatial distributions between the current situation and zero export (Figure 4), the basic pattern has not changed. The coastal regions are still the main regions with industrial agglomeration. Disparity in the coastal regions and the inland has not changed. The largest difference is reflected in the northeast being a new concentrated region. Obvious path dependency exists to certain degree during industrial development. Only the change in the export environment may revise the industrial growth in some regions; but it is not enough to be the only condition to change the basic spatial pattern.

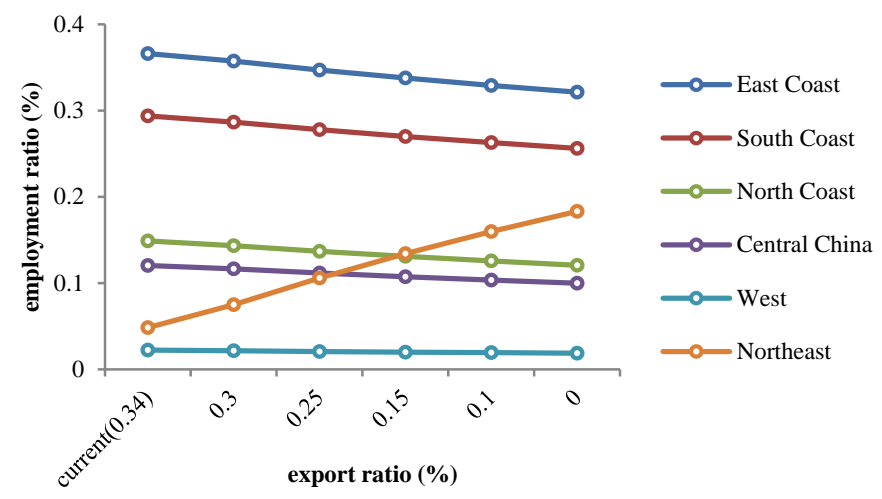

Figure 2. Varying employment share of garments \& other fiber products industry across regions along with its decreasing export ratio

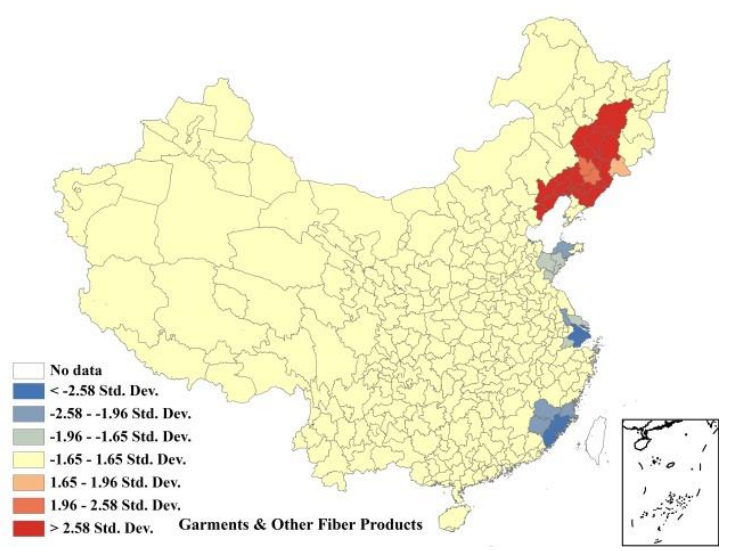

Figure 3. Spatial pattern of hotspot in terms industrial growth of garments \& other fiber products industry in China
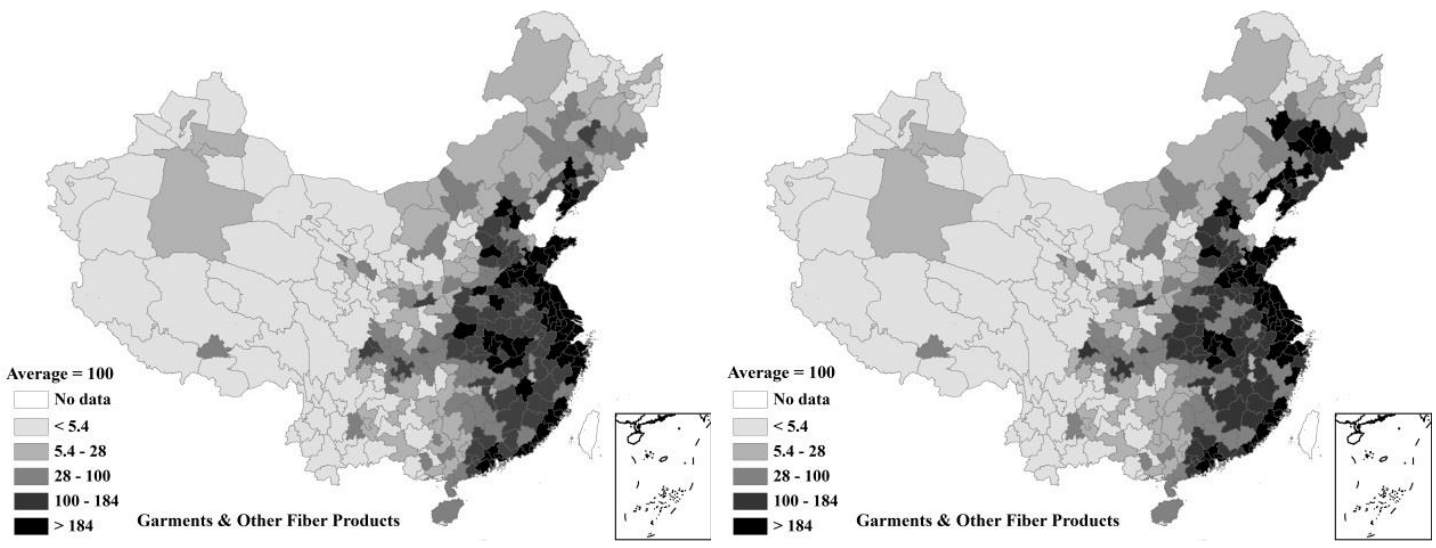

Figure 4. Total employment across regions for garments \& other fiber products industry in China: current (left) and no export (right)

In addition, it is meaningful to see if the decreasing export of one industry would change the spatial distribution of its upstream industry. Therefore, we further analyze the impact of decreasing export ratio of the garments industry on the spatial evolution of its main upstream industry, the textile industry. Indicated by Figure 5, the inter-regional relocation 
of the textile industry is evident due to the reduction in the export ratio of garments industry, and the general trend is in line with the garments industry. The industrial share in the northeast regions significantly increases, while it reduces to some extent in other regions. However, the change in trend is not as remarkable as that of the garments industry. Seeing from the spatial pattern of the hotspots (Figure 6), the coastal regions like Yangtze River Delta and Shandong Peninsula are the main regions experiencing recession, while most regions of Liaoning and Jilin in the northeast are the main growth regions. However, on comparing the industrial spatial distributions in context of the current situation and zero export (Figure 7), the basic pattern has not been reversed as above, and the disparity in the coast and the inland persists. In combination with the above analysis on the garments industry, we found that a change in the export environment of one industry could reform the location itself as well as change the spatial distribution of its closely connected upstream industry, although to a smaller extent.

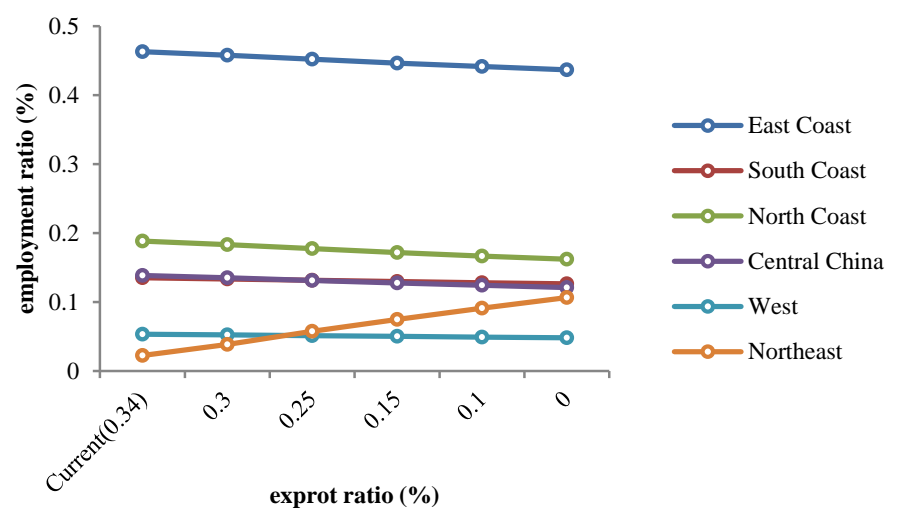

Figure 5. Varying employment share of textile industry across regions along with decreasing export ratio of garments \& other fiber products industry

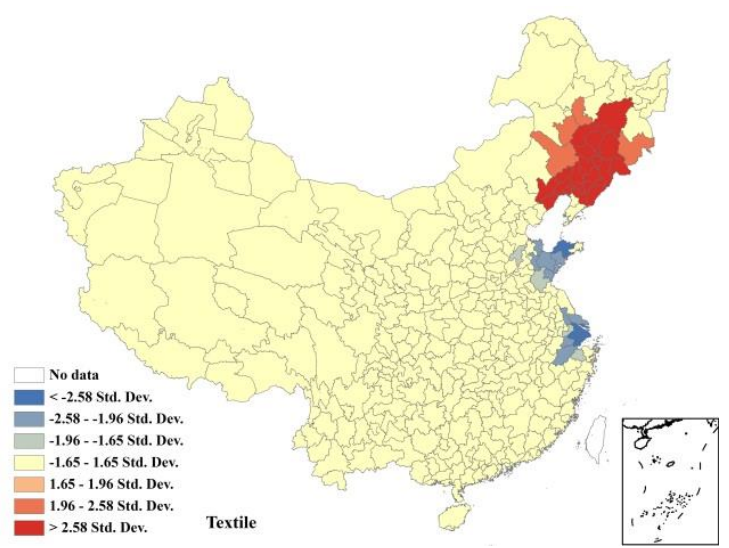

Figure 6. Spatial pattern of hotspot in terms industrial growth of textile industry in China

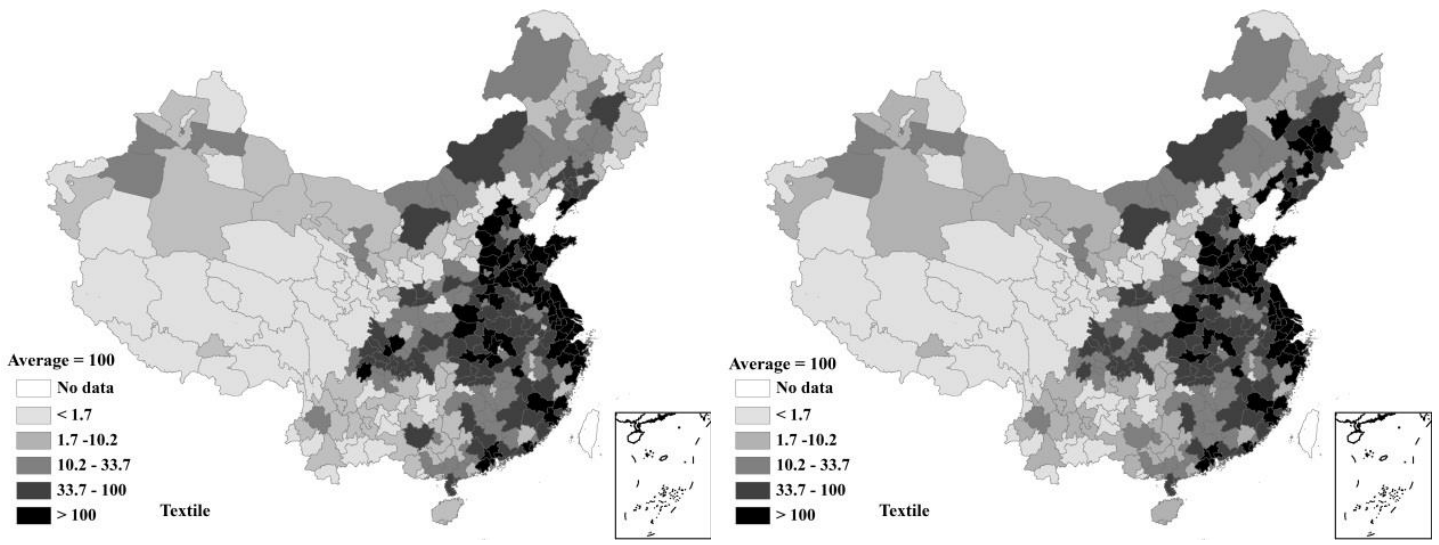

Figure 7. Total employment across regions for textile industry in China: current (left) and no export (right)

4.2.2 Simulation for Spatial Evolution of Intermediate Goods and Its Downstream Industry

Next, we take a simulation that the spatial evolution of the intermediate goods industry and its downstream industry 
follow a procedure similar to the final consumption goods industry. However, different results have been found with features of location change. Figure 8 describes the ratio changes of each region in the entire country in terms of employment under a continuous decline in export of the electric equipment and machinery industry. The result shows that under the current export ratio, the industry is mainly concentrated in the coastal regions, especially east coast where employment accounts for almost $38 \%$ of the entire country, while a few are distributed in central China, the northeast and the west regions. However, with the reduction in export ratio, the west has been the main growth region along with being a fast-growing employment area in China; besides, the share of the south coast has witnessed a slight increase, while the other regions have experienced a severe reduction in employment. Under the assumed situation of zero export, the west has been the main industry region, only second to the east coast and south coast in terms of employment. Through further detailed analysis of the spatial pattern of industrial growth hotspots under the current situation and zero exports, as shown in Figure 9, the industry grows faster mainly to the south of Shan'xi and east of Gansu in the west, and a part of the Pearl River Delta, while industry recession mainly occurs in the coastal regions like the Yangtze River Delta and the Shandong Peninsula. However, on comparison of the spatial distribution in current situation with that in zero export (Figure 10), it is observed that the basic spatial pattern has not been reversed, and the disparity in the coast and inland has been sustained. Industry is still concentrated in the coastal regions, especially the Yangtze River Delta, Shandong Peninsula, Pearl River Delta, and a few regions in central-west China. The biggest change is reflected in the dispersion of industrial agglomeration in the south of Shan'xi in the west. Thus, the obvious path dependence during regional industrial development has been reconfirmed. Evolution of the industrial location is a complicated spatial effect process, and changes in the export environment are one of the influencing factors.

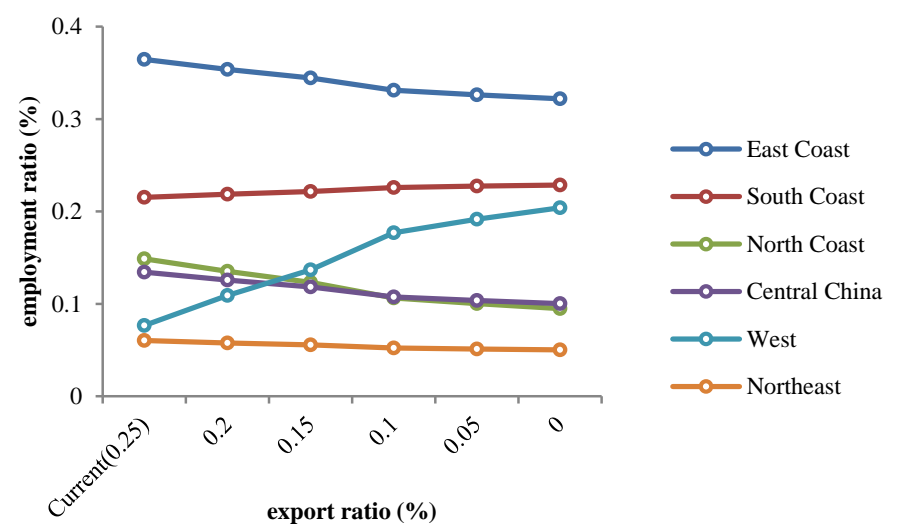

Figure 8. Varying employment share of electric equipment \& machinery industry across regions along with its decreasing export ratio

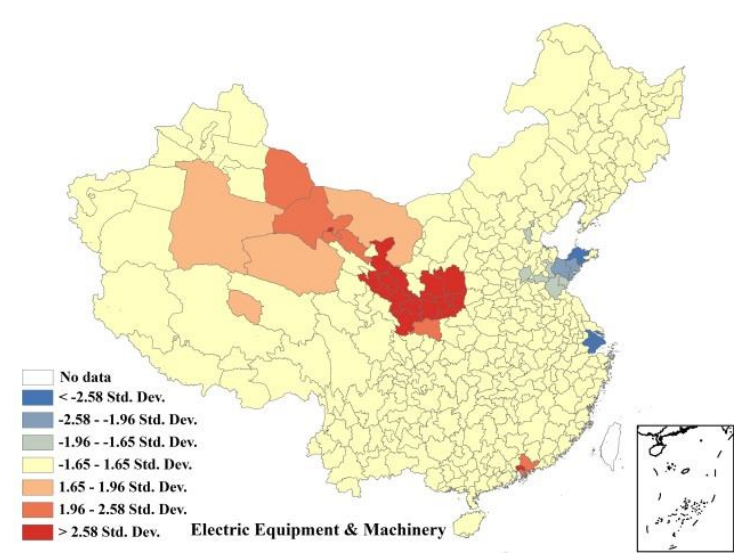

Figure 9. Spatial pattern of hotspot in terms industrial growth of electric equipment \& machinery industry in China 


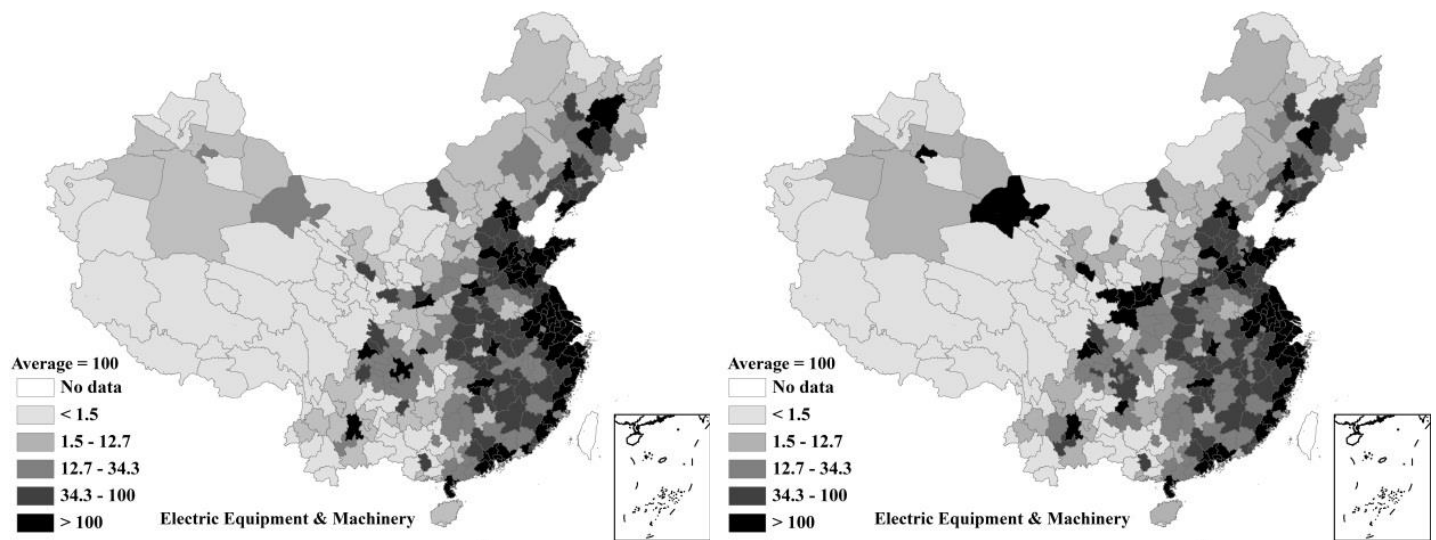

Figure 10. Total employment across regions for electric equipment \& machinery industry in China: current (left) and no export (right)

Similarly, we further investigate the impact of decreasing export ratio of the intermediate goods industry on its downstream industry. Therefore, we analyze the relation between the decreasing export ratio of electric equipment and machinery industry, and the spatial pattern change of its main downstream industry, the electronic and telecommunications industry. As indicated by Figure 11, spatial distribution of the electronic and telecommunications industry has changed along with the reduction in export ratio of electric equipment and machinery industry, and the general trend is similar to that of its upstream industry, the electric equipment and machinery industry. However, there is a slight difference in the extent of changes. The share of employment in the west also grows at a slightly slower rate while the south coast grows faster than that of its upstream industry. Further investigation from the spatial pattern of hotspots with regard to regional industrial growth (Figure 12) reveals that the coastal regions like Yangtze River Delta, Shandong Peninsula and the capital regions are the main areas experiencing recession, while the south of Shan'xi and east of Gansu in the west, and a part of the Pearl River Delta are the main regions with significant industrial growth. However, similar to its upstream industry, the basic spatial pattern has not reversed, and the disparity in the coast and inland has been relatively stable on comparison of the industrial spatial distribution in the current situation with zero export (Figure 13). Industry is concentrated in the coastal regions, especially the Yangtze River Delta, Shandong Peninsula, Pearl River Delta and a few regions in the central-west in both the current and zero export situations. The difference is mainly in the expansion of the industrial concentration areas in the central-west regions. In combination with the above analysis, we could conclude that changes in the export environment of a given industry would result in a change of location as well as spatial distribution of its downstream industry.

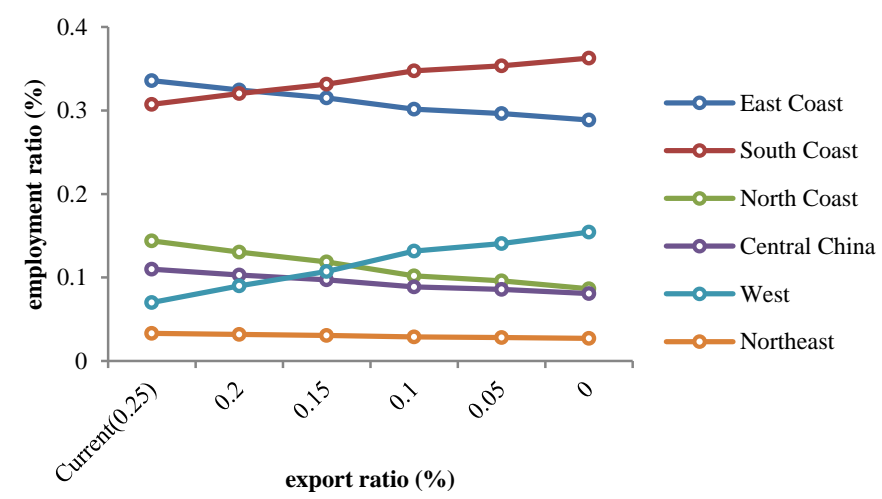

Figure 11. Varying employment share of electronic \& telecommunications industry across regions along with decreasing export ratio of electric equipment \& machinery industry 


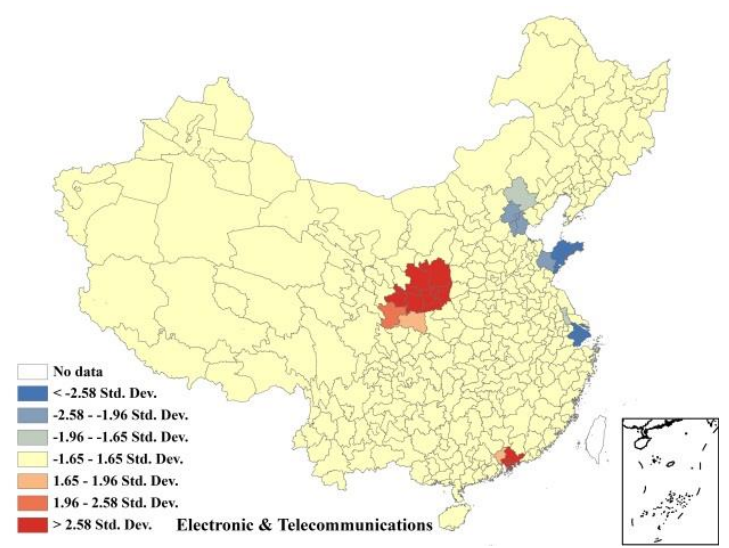

Figure 12. Spatial pattern of hotspot in terms industrial growth of electronic \& telecommunications industry in China
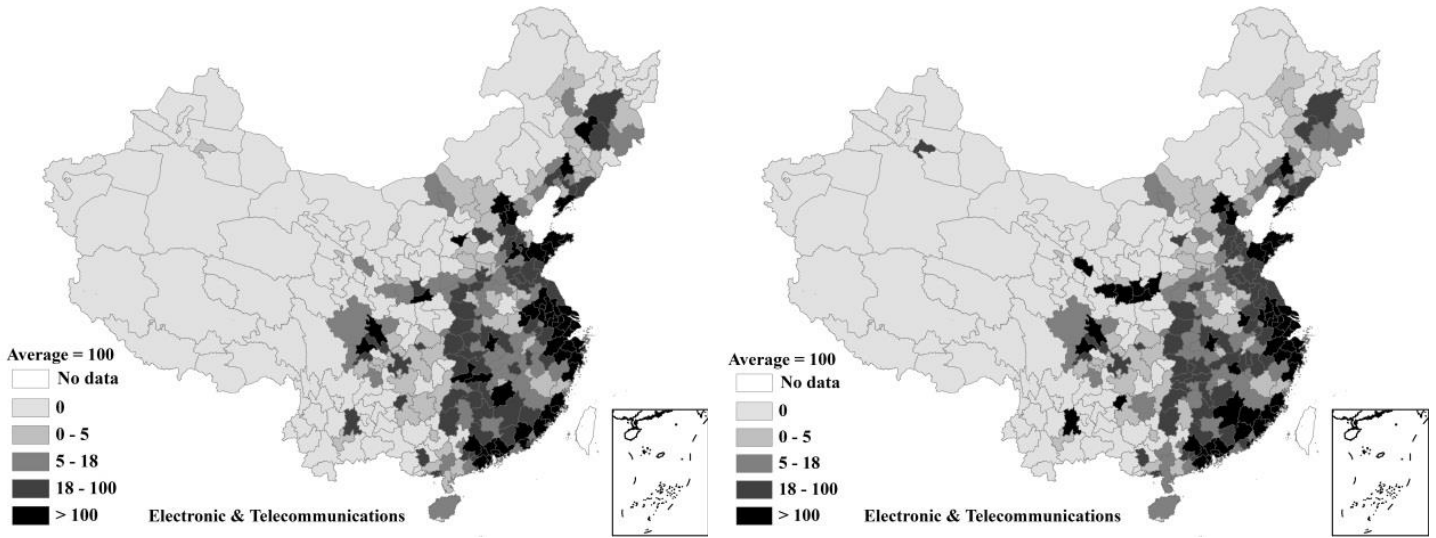

Figure 13. Total employment across regions for electronic \& telecommunications industry in China: current (left) and no export (right)

\section{Conclusion}

This study mainly analyzes the influence of a decline in exports of China to the internal distribution of industries, by adopting a tractable economic geography model under the framework of new economic geography. There is a non-negligible influence on the spatial pattern of economic activities if there is a decline in export. Besides, the influences are different across industries industry comparison based on final consumption goods and the intermediate input products. Although most industries in China present similar spatial pattern of coastal-inland gradient, the changes in foreign trade will not lead to locational evolution in the same direction. Our study also indicates that the export change of one industry will result in a change to its own location as well as its closely linked upstream and downstream industries; however, the extent of change of the spatial evolvement is different. Hence, the input-output relation is an important force that shape spatial pattern.

However, further research found that although the industrial location changes to a certain degree due to a decline in export, the basic spatial pattern has remained stable. Economic activities are still concentrated in coastal regions, especially the Yangtze River Delta and Pearl River Delta, while there is very little industrial activity in central and western China. This indicates that the determination of industrial location is a complicated mechanism. Coastal-inland disparity of industries formed since the policy reform and trade liberalization will not be reversed only due to change in export. According to new economic geography, high economic-density regions, home-market effect, forward-backward linkage, and agglomeration economies are centripetal forces for industrial location; and a decline in export will not alter the centripetal forces. We should have an accurate understanding of economic crisis, and the influence of decreasing export that a country may possibly face in the future. Decline in foreign trade does not result in a remarkable reshaping of economic geography between the coast and the inland. The industrial location is determined by multiple factors. Although decreasing foreign trade may weaken the geographical difference between the coast and the inland, the endogenous difference among regions accumulated since initial development may not be affected in the short run.

The main contribution of our study is to propose a tractable economic geography model to analyze the impact of changing export on the internal economic geography of a country. Predictability of the model makes policy implications more practicable. In addition, as Combes and Lafourcade (2011) argued, this approach has the advantageous feature of being easy to replicate for other countries. Moreover, this approach could be used on other research by setting different 
variables with a specific significance. Despite this, our research has certain limitations. We have assumed the current trade environment for other industries when analyzing the impact of decreasing export on a single industry. Essentially, it is probable that an industry facing change at the same time as another industry will cause a corresponding change in the others, making the evolvement of spatial pattern much more complicated. Hence, a simplified analysis such as our study will jeopardize the prediction robustness of the model. Therefore, we hope this study will inspire further research.

\section{Acknowledgement}

This work was supported by National Natural Science Foundation of China under Grant [No. 41501132]; China Postdoctoral Science Foundation under Grant [No.2015M581051].

\section{References}

Alonso-Villar. (1999). Spatial distribution of production and international trade: A note. Regional Science and Urban Economics, 29(3), 371-380. http://dx.doi.org/10.1016/S0166-0462(98)00041-6.

Brülhart, M. (2011). The spatial effects of trade openness: a survey. Review of World Economics, 147(1), 59-83. http://dx.doi.org/10.1007/s10290-010-0083-5

Brülhart, M., Crozet, M., \& Koenig, P. (2004). Enlargement and the EU periphery: the impact of changing market potential. The World Economy, 27(6), 853-875. http://dx.doi.org/10.1111/j.1467-9701.2004.00632.x

Cai, F. (2009). The impact of financial crisis on manufacturing industries: the catching up opportunity for Central \& Western China. Economic Perspectives, (2), 4-8.

Combes, P. P., \& Lafourcade, M. (2001). Transport costs decline and regional inequalities: evidence from France. $C E P R$ Discussion Paper, 2894.

Combes, P. P., \& Lafourcade, M. (2011). Competition, market access and economic geography: Structural estimation and predictions for France. Regional Science and Urban Economics, 41, 508-524. http://dx.doi.org/10.1016/j.regsciurbeco.2011.03.012

Crozet, M., \& Soubeyran, P. (2004). EU enlargement and the internal geography of countries. Journal of Comparative Economics, 32, 265-279. http://dx.doi.org/10.1016/j.jce.2004.02.009

Fujita, M., \& Hu, D. P. (2001). Regional disparity in China 1985-1994: The effects of globalization and economic liberalization. The Annals of Regional Science, 35, 3-37. http://dx.doi.org/ 10.1007/s001680000020

Haaland, J., \& Norman, V. (1992). Global production effects of European integration, in Trade Flows and Trade Policies (ed. L. Winters), Cambridge: Cambridge University Press, 67-88.

Hanson, G. H. (1998). Regional adjustment to trade liberalization. Regional Science and Urban Economics, 28(4), 419-444. http://dx.doi.org/10.1016/S0166-0462(98)00006-4

He, C. F., \& Xie, X. Z. (2006). Geographical Concentration and Provincial Specialization of Chinese Manufacturing Industries. Acta Geographica Sinica, 61(2), 221-222.

http://www.cnki.net/KCMS/detail/detail.aspx?QueryID=0\&CurRec=2\&dbcode=CJFQ\&dbname=CJFD2006\&filen ame=DLXB200602009\&urlid=\&yx=\&v=MzAxMDZ5ZllPWnFGQ2puVzc3TklTSFRiTEc0SHRmTXJZOUZiW VI4ZVgxTHV4WVM3RGgxVDNxVHJXTTFGckNVUkw=

He, C. F., Pan, F. H., \& Sun, L. (2007). Geographical Concentration of Manufacturing Industries in China. Acta Geographica Sinica, 62(12), 1253-1264.

Hu, W., \& Zhang, Y. (2015). The evolution of Domestic Spatial Pattern of China's Foreign Trade: an Empirical Study on the Panel Data of 1994-2012. International Economics and Trade Research, 31(3), 16-30. http://dx.doi.org/10.13687/j.cnki.gjjmts.2015.03.002

Huang, J. L. (2011). "Foreign trade, interregional trade and regional specialization." [In Chinese] South China Journal of Economy, (6), 7-22.

Huang, J. L., \& Li, K. W. (2006). Foreign Trade, Local Protectionism and Industrial Location in China. China Economic Quarterly, 3(5), 733-760. http://dx.doi.org/ 10.13821/j.cnki.ceq.2006.02.016

Isard, W. (1956). Location and space-economy. Massachusetts M. I. T. Press.

Krugman, P., \& Livas, E. (1996). Trade policy and third world metropolis. Journal of Development Economics, 49(1), 137-150. http://dx.doi.org/ 10.1016/0304-3878(95)00055-0

Liu W., Liu, H., Tang, Z., \& Wang, L. (2010). The Impacts of Exports on Regional Economic Development and Industrial Restructuring in China. Acta Geographica Sinica, 65(4), 407-415. 
Liu, W. D., Clifton, P., \& Liu, H. G. (2009). The global economic crisis and China's foreign trade. Eurasian Geography and Economics, 50(5), 497-512. http://dx.doi.org/ 10.2747/1539-7216.50.5.497

Liu, W. D., Zhang, G. Q., \& Song, Z. Y. (2007). Trend of Spatial Configuration Evolvement of Economic Development in China under Globalization. Scientia Geographica Sinica, 27(5), 609-616. http://dx.doi.org/10.13249/j.cnki.sgs.2007.05.016

Paluzie, E. (2001). Trade policy and regional inequalities. Papers in Regional Science, 80(1), 67-85. http://dx.doi.org/10.1111/j.1435-5597.2001.tb01787.x

Smith, A., \& Venables, A. J. (1998). "Completing the internal market in the European Community, Some industry simulations." European Economic Review, 32, 1501-1525. http://dx.doi.org/ 10.1016/0014-2921(88)90113-4.

Teixeira, A. C. (2006). Transport policies in light of the new economic geography: the Portuguese experience. Regional Science and Urban Economics, 36, 450-466. http://dx.doi.org/10.1016/j.regsciurbeco.2006.01.002

Tomiura E. (2003). Changing economic geography and vertical linkages in Japan. Journal of the Japanese and International Economies, 17(4), 561-581. http://dx.doi.org/ 10.1016/S0889-1583(03)00063-7

Wen, M. (2004). Relocation and agglomeration of Chinese industry. Journal of Development Economics, 73(1), 329-347. http://dx.doi.org/ 10.1016/j.jdeveco.2003.04.001

World Bank. (2009). Reshaping Economic Geography. Washington, DC: The World Bank.

Xu, Y. D., \& Liang, Q. (2012). Trade cost and internal industrial geography. China Economic Quaterly, 11(2), 1113-1136. http://dx.doi.org/ 10.13821/j.cnki.ceq.2012.03.011

Zuo, T., \& Paget, M. (2015). Regional Development Model and Regional Convergence: Empirics on Panel data of 7 regions in China. Inquiry into Economic Issues, (3), 96-101. http://dx.doi.org/10.3969/j.issn.1006-2912.2015.03.015

\section{Appendix 1}

Locational Gini index is a measurement of geographical concentration, which is calculated as follows:

$$
G_{i}=\frac{1}{2 n^{2} s_{i}} \sum_{k=1}^{n} \sum_{j=1}^{n}\left|s_{i j}-s_{i k}\right|
$$

where $S_{i j}$ is the share of industry $i$ in region $j, S_{i k}$ is the share of industry $i$ in region $k, n$ is the number of regions and $S_{i}$ is the mean of shares. The closer the distribution of industry $i$ reaches to a uniform distribution, the smaller the index will be. If an industry is equally distributed across all regions the index will equal zero. An index close to one suggests that an industry is entirely concentrated in a region (Wen, 2004).

\section{Appendix 2}

The Getis-Ord $\mathrm{G}^{*}$ statistics is able to detect if there are statistically significant clusters of a given phenomenon. This statistic identifies "hot spots", or concentrations in spatial distributions in which areal units and their neighbors have similar values of a given phenomenon.

$$
G_{i}^{*}(d)=\frac{\sum_{j=1}^{n} W_{i j} X_{j}}{\sum_{j=1}^{n} X_{j}} \quad Z\left(G_{i}^{*}\right)=\frac{G_{i}^{*}-E\left(G_{i}^{*}\right)}{\sqrt{\operatorname{Var}\left(G_{i}^{*}\right)}}
$$

where $X_{j}$ is the observed value of $X$ at location $j, W_{i j}$ is a symmetric one/zero spatial weight matrix with ones for all links defined as being neighbored to each other, and with zeros for not adjacent links. $E\left(G_{i}^{*}\right)$ is mathematic expectation of $G_{i}^{*}$, and $\operatorname{Var}\left(G_{i}^{*}\right)$ is variation of $G_{i}^{*} . Z\left(G_{i}^{*}\right)$ is standardized value of $G_{i}^{*}(d)$. A large positive $Z\left(G_{i}^{*}\right)$ implies that large values of $X_{j}$ are adjacent to point $i$ (hot spots). A large negative $Z\left(G_{i}^{*}\right)$ means that small values of $X_{j}$ are adjacent to point $i$ (cold spots).

\section{(c)) EY}

This work is licensed under a Creative Commons Attribution 3.0 License. 